\title{
Assessing the impact of removing reserve status on the Abore Reef fish assemblage in New Caledonia
}

\author{
Jocelyne Ferraris $^{1}$, Dominique Pelletier ${ }^{2, *}$, Michel Kulbicki ${ }^{1}$, Claude Chauvet ${ }^{3}$ \\ ${ }^{1}$ IRD \% Université de Perpignan, 66860 Perpignan, France \\ ${ }^{2}$ Laboratoire MAERHA, IFREMER, BP 21105, 44311 Nantes Cedex 3, France \\ ${ }^{3}$ LERVEM, Université de Nouvelle-Calédonie, BP 4477, Nouville, Nouméa, Nouvelle-Calédonie
}

\begin{abstract}
We propose a statistical approach based on multivariate analysis and general linear models to test the consequences of removal of reserve status from the Abore Reef fish assemblage of the Abore Reef reserve, New Caledonia. Consequences on fish density were examined at the level of fish assemblage, accounting for habitat. Fish counts and habitat-related information were collected before and after the removal of reserve status, both inside and outside the reserve. Species groups were constructed on the basis of additional information on behavioural characteristics and taxonomy. The impact of the removal of reserve status was assessed by using 2 habitat proxies corresponding to 2 spatial scales and by considering several criteria for grouping species. Habitat appeared to be a determining factor in explaining density variations. Significant positive effects were found for several species groups such as macrocarnivores, piscivores, herbivores, Lethrinidae and Siganidae. A counterintuitive negative effect was observed for Acanthuridae. No significant differences between the area which remained closed to fishing and the area open to fishing were found for the other species groups. The approach allows for a synoptic diagnosis of the impact of changes in reserve status at the fish assemblage level. It could be used to develop and select potential indicators for monitoring such impacts on fish assemblages in coral reef ecosystems and in other contexts.
\end{abstract}

KEY WORDS: Marine reserve $\cdot$ Reef fish assemblage $\cdot$ Habitat $\cdot$ Coral reefs $\cdot$ Fishing impact $\cdot$ Ecological indicator $\cdot$ South Pacific

\section{INTRODUCTION}

Reef fish communities are major resources for inshore fisheries all over the world. In coastal regions, the demand for food sharply increased in the last few decades in relation to growing demographic pressure and the majority of coastal resources are now overexploited (FAO 1995). In the Pacific islands, subsistence fishing represents about $80 \%$ of total coastal catch in the reef and lagoon fisheries (Dalzell et al. 1996). These ecosystems must be protected against the detrimental effects of increased fishing, urbanisation and tourism.

The impact of fishing on the ecosystem has yet to be evaluated. Scientific assessments of fish resources are mostly monospecific and account neither for the struc- ture of the ecosystem nor for spatial heterogeneities. A more holistic approach, accounting for species interactions and environmental forcing, has been recommended for the management of fisheries and coastal ecosystems (Botsford et al. 1997, Pitcher et al. 1998). The structure and functioning of reef fish communities are poorly understood, especially in coral reef ecosystems which exhibit a very high diversity of fish species (Bell \& Galzin 1984, Chabanet et al. 1997, Jones \& Syms 1998, Ohman et al. 1998). For demersal and benthic species, spatial distributions of populations is tightly linked to habitat preferences. To better understand these fish communities, several complementary approaches have been envisaged: (1) spatially explicit modelling of the dynamics of populations and exploitation (see e.g. Pelletier et al. 2001, Gerber et al. 2003); 
(2) global approaches at the ecosystem level, both in terms of modelling (Christensen \& Pauly 1992) and management advice (Agardy 2000); and (3) experimental approaches which aim at improving knowledge about the ecosystem and its response to fishing through deliberate manipulation of exploitation rates, i.e. actively adaptive management in the sense of Walters \& Hilborn (1976).

The implementation of natural laboratories for this purpose has been facilitated by the existence or the establishment of marine reserves (Russ \& Alcala 1996). Marine reserves are also increasingly regarded as management measures that may contribute to sustainable use of resources and ecosystem protection (Agardy 2000, Sumaila et al. 2000). There have been many articles presenting the advantages of marine reserves for resource management and ecosystem conservation (Roberts \& Polunin 1991, Dugan \& Davis 1993, Allison et al. 1998, Lauck et al. 1998, Roberts et al. 2001). The main effects expected from the establishment of reserves are, on the one hand, increased abundances and biomasses of spawning stocks, and recruitment inside the protected area and in surrounding areas through spillover, and on the other hand, restoration of ecosystems through protection of habitat from fishing gears (see e.g. last cited papers above). The actual efficiency of a reserve must be assessed from appropriate indicators of resources, fish communities and habitat.

Many studies have assessed the impact of reserves on fish populations and on marine organisms (see e.g. reviews in Roberts \& Polunin 1991, Russ 2002, Halpern 2003). The majority of these studies pertain to coral reef ecosystems. Most papers are interested in assessing the direct effects of reserves, i.e. differences in density, biomass and species richness between the reserve and a comparable zone.

In general, the results show significant differences for particular species (Bell 1983, Paddack \& Estes 2000, see also other references in review papers cited above), taxonomic families (e.g. Alcala 1988, Jennings et al. 1996, Letourneur 1996, Wantiez et al. 1997a), or other groups of species, e.g. large predators (Russ \& Alcala 1996, Chiappone et al. 2000). Significant differences are more likely observed when the reserve has already been in place for several years (Alcala 1988, Paddack \& Estes 2000). In many cases, however, nonsignificant results have been obtained for a substantial number of species, genera or taxonomic families (e.g. Rakitin \& Kramer 1996, Chapman \& Kramer 1999, Paddack \& Estes 2000), in particular in recently established reserves (Alcala 1988).

A few remarks about assessment methodology may be noted from existing literature. One issue pertains to the lack of initial evaluation. In a large number of stud- ies, the initial state of the fish community was not assessed before establishing the reserve. Abundance and other biological variables inside the reserve were compared to those in a reference zone, i.e. from a Control-Impact design (e.g. Harmelin et al. 1995, Letourneur 1996). Spatial and temporal heterogeneities of ecosystems lead to confusion of protection effects with environmental effects such as those linked with habitat structure (Samoilys 1988, García-Charton \& Perez-Ruzafa 1999, see also next paragraph), and make it necessary to rely on designs that include measurements before and after establishment of the reserve, inside and outside of the reserve.

A second issue relates to habitat effects. Habitat is a determinant in explaining the spatial distribution and structure of fish communities (McCoy \& Bell 1991, Sale 1998). Accounting for habitat is crucial for comparing abundances in distinct zones, which is necessary to assess reserve effects. Monitoring habitat itself should be part of the assessment (Ward et al. 1999), and each habitat should be sampled (García-Charton et al. 2000). Relatively few reserve assessments have explicitly considered habitat. In several instances, differences in densities were tested by habitat type (e.g. Letourneur et al. 1997). Paddack \& Estes (2000) compared fish assemblages between sites, while accounting for substratum composition. Sometimes, an additional factor related to habitat was included in the model, such as depth (Bell 1983, García-Rubies \& Zabala 1990, Kelly et al. 2000), reef type (Chapman \& Kramer 1999), or some other definition of habitat (McCormick \& Choat 1987, Castilla \& Bustamante 1989, García-Charton et al. 2004).

A further issue relates to the diagnosis of reserve effects. Direct effects are, in general, assessed by comparing densities, biomasses, mean size or diversity indices, between the reserve and the exploited area. Statistical tests are carried out independently for some species or species groups of interest. These results are helpful for a better understanding of the response of some particular species to reserve protection. However, they do not provide a synoptic view of the impact of the reserve, and do not allow a comparison of the sensitivities of different fish community components to reserve status. Assessing the impact of a reserve at the fish community level would be more desirable in providing scientific elements for an ecosystem approach to management (Botsford et al. 1997, Jennings \& Kaiser 1998, Pitcher et al. 1998), including the construction of ecological indicators of reserve effects (Pelletier et al. 2004).

In this paper, we assessed the impact of the partial removal of reserve status on the Abore reef fish assemblage (New Caledonia). The assessment was carried out at the level of the fish assemblage, explicitly 


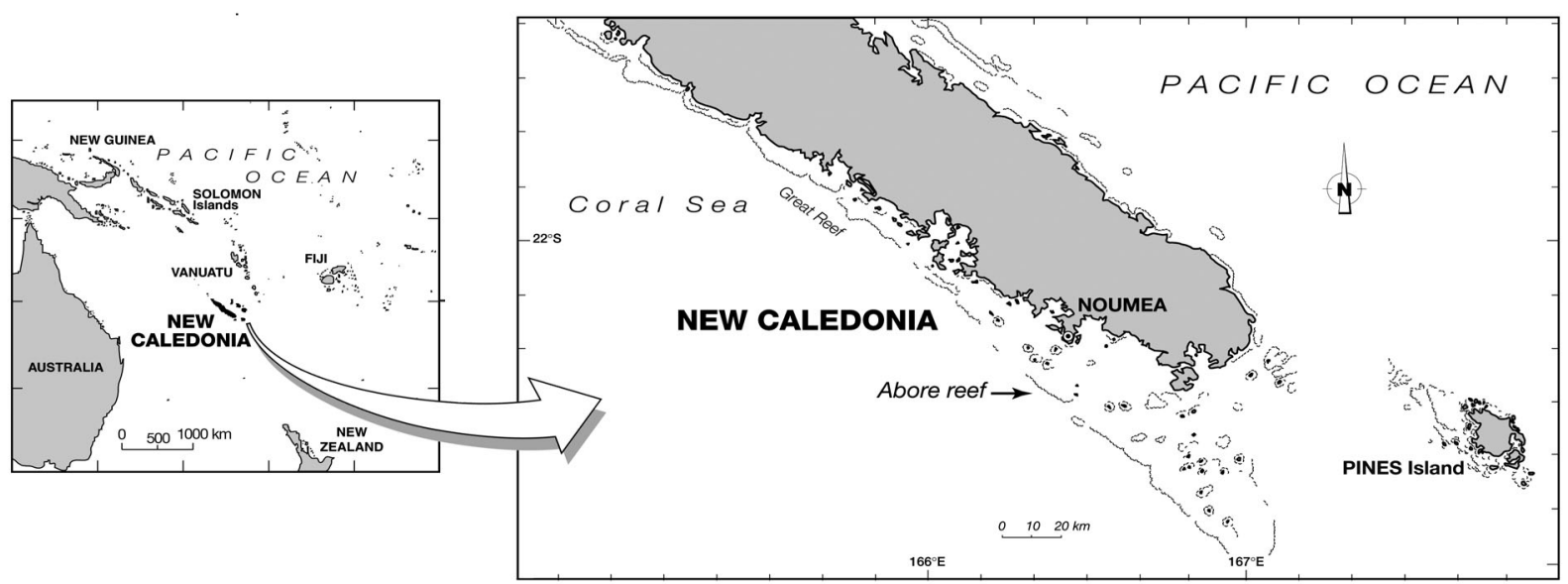

Fig. 1. Location of the area studied within the Noumea lagoon

accounting for habitat. In the first step, species groups were constructed on the basis of behavioural characteristics and taxonomy, while habitat proxies were defined from environmental data. In the second step, we tested for the impact of the removal of reserve status on fish density. By simultaneously considering the different components of the fish assemblage, the models used provide a synoptic approach to appraising the impact of reserve status. was finally closed to fishing from August 1995. In this study, we assessed the effect on the reef fish assemblage of partially removing reserve status between 1993 and 1995.

Data. The impact of the removal of reserve status on fish assemblages was monitored from a survey involving only 1 date before and 1 date after the impact. The area open to fishing from August 1993 is the 'impact' area (Area B in Fig. 2), while in the 'control' area fish-

\section{MATERIALS AND METHODS}

Study area. The Noumea lagoon, located in SW New Caledonia, South Pacific (Fig. 1), is a large coral reef ecosystem where several marine reserves were established in the 1980s to protect the coral reef ecosystem from damage due to fishing and other human activities.

We focused on the Abore Reef reserve, located on a $25 \mathrm{~km}$ long barrier reef, ca. 15000 ha. Fishing was banned from the whole reef from 1990 to 1993, and allowed again on two-thirds of the reef from August 1993 for a fishing experiment. The Natural Resource Department of the South Province, in charge of the management of the lagoon reserves, monitored the experiment. Release of the ban immediately resulted in high fishing pressure; in the first $2 \mathrm{wk}$, the number of boats and fish yield reached levels which had previously been observed over an entire year (Sarramegna 2000). Monitoring the fishing effort and catch rates showed that the benefits from the 1990 to 1993 ban were dissipated within a few weeks. The whole reef

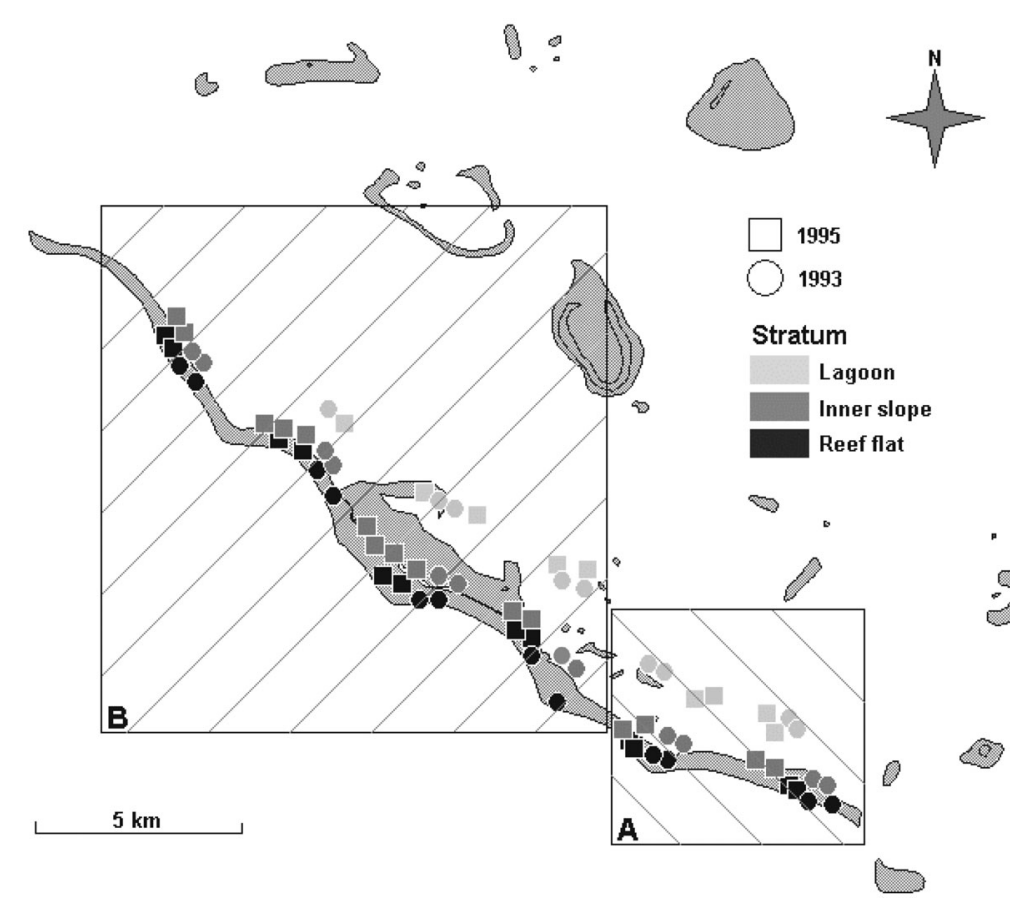

Fig. 2. Experimental design of the survey. The control area (Area A) has been a reserve area since 1990, whereas the impact area (Area B) was open to fishing from 1993 to 1995 following a 3 yr fishing ban (see sampling design in Table 1). Transects were identified by year and reef zone 
ing has been permanently banned since 1990 (Area A in Fig. 2). A survey was conducted in July 1993 and July 1995, immediately before the opening and immediately before the final closure, respectively (Letourneur et al. 1997). The experimental design rests on a stratification of the reef into 3 morphological zones: reef flat, inner slope and lagoon (Fig. 2), delineated on aerial photographs. The lagoon stratum corresponds to the area located behind the reef slope, composed of flat sandy bottoms with scattered coral patches, with an average depth of $8.4 \mathrm{~m}$. The reef flat is a very shallow area ranging from 0.7 to $1.5 \mathrm{~m}$, whereas the inner slope of the reef is intermediate between the flat and the lagoon, with spurs and grooves (Batistini et al. 1975). Fish assemblages differ among reef zones. For each year of survey, 6 sampling sites were selected in each reef stratum. They were regularly spaced along the reef to ensure a good longitudinal coverage (Fig. 2, approximate distance between 2 adjacent sites was $2 \mathrm{~km}$ ). At each site, at least 2 transects, $500 \mathrm{~m}$ apart, were sampled, with the exception of 2 stations in the northern part of the lagoon of Area B where reef development was insufficient to allow replication. In total, 69 transects were sampled: 12 per year in the control area (Area A); and 21 and 24 in 1993 and 1995, respectively in the impact area (Area B) (Table 1).

Observations consisted of underwater visual censuses (UVC) carried out by 2 scuba divers along a $50 \mathrm{~m}$ linear transect. Each fish observed was identified to species level. For each species, density (ind. $\mathrm{m}^{-2}$ ) and biomass $\left(\mathrm{g} \mathrm{m}^{-2}\right)$ were calculated by the method described in Kulbicki \& Sarramegna (1999). A total of

Table 1. Distribution of transects according to year, reserve and habitat proxies (reef zone and local habitat). The 2 missing transects (see total) in the last 2 columns correspond to transects where no environmental data were collected

\begin{tabular}{|c|c|c|c|c|c|}
\hline \multirow[t]{2}{*}{ Reserve } & \multicolumn{2}{|c|}{ Reef zone } & \multicolumn{3}{|c|}{ Local habitat } \\
\hline & 1993 & 1995 & & 1993 & 1995 \\
\hline \multicolumn{6}{|l|}{ A } \\
\hline Reef flat & 4 & 4 & Hab $1+2$ & 1 & 1 \\
\hline Inner slope & 4 & 4 & Hab 3 & 1 & 4 \\
\hline \multirow[t]{3}{*}{ lagoon } & 4 & 4 & Hab 4 & 4 & 3 \\
\hline & & & Hab 5 & 3 & 0 \\
\hline & & & Hab 6 & 3 & 3 \\
\hline Sub-total A & 12 & 12 & & 12 & 11 \\
\hline \multicolumn{6}{|l|}{ B } \\
\hline Reef flat & 8 & 8 & Hab $1+2$ & 6 & 9 \\
\hline Inner slope & 8 & 11 & Hab 3 & 6 & 9 \\
\hline \multirow[t]{3}{*}{ lagoon } & 5 & 5 & Hab 4 & 1 & 3 \\
\hline & & & Hab 5 & 5 & 3 \\
\hline & & & Hab 6 & 2 & 0 \\
\hline Sub-total B & 21 & 24 & & 20 & 24 \\
\hline Total & 33 & 36 & & 32 & 35 \\
\hline
\end{tabular}

374 species were identified during the survey. The number of species observed at a given transect often exceeded 100, most species being encountered only at a few transects. Along each transect, environmental data were recorded independently of fish counts. Eighteen variables were measured at each transect, including 10 substratum categories, 3 depth variables and 5 types of living epibenthos (including algae and coral). Substratum and living epibenthos were expressed in percent cover of the bottom area. A third set of data concerned diet composition, mobility and lifehistory characteristics of 1393 species recorded in previous studies carried out in the New Caledonia region (Kulbicki \& Rivaton 1997). This information came from 2 databases, FISHBASE (Pauly \& Froese 1991) and FISHEYE (Labrosse et al. 1999).

Methodology. We aimed at testing the impact of the removal of reserve status on the whole fish assemblage, while accounting for spatial variability in habitat. Possible differences in habitat between transects were quantified through habitat proxies based (1) on reef zones and (2) on environmental data. The large number of species observed made it difficult to analyse changes at the species level. Choosing criteria for grouping species raised the question of defining partitions of the fish assemblage that would be relevant to the impact of reserve status. The variables used for testing this impact (e.g. species richness, presence/ absence of a species group, density, biomass) should be chosen depending on how reserve status (and conversely fishing) is likely to affect fish, e.g. increased densities, larger fish, modified interspecific relationships. Both the criteria and the variables define a set of metrics. Here, we focused on the density variable and on several criteria for partitioning the fish assemblage (referred to below as partitioning criteria).

The methodology proposed consists of 2 steps (Fig. 3). First, an exploratory step allowed us to assign a habitat to each transect on the basis of environmental information, and to group species according to a range of criteria deemed relevant for reserve effect assessment. In the second step, habitat and species group were used as explanatory factors in inferential models of density-related metrics. Models were used to test the impact of the removal of reserve status upon the fish assemblage, and to compare the sensitivities of metrics corresponding to different species groups. The whole methodology can be seen as providing a contribution to identifying potential indicators at community level for assessing ecological effects of reserve status.

Defining habitat. Two habitat proxies were used. At the reef scale, the proxy was the reef zone (reef flat, inner slope and lagoon), defined prior to the survey from aerial photographs. It reflects the general geomorphology of the reef, and implicitly takes into 
account depth, substratum rugosity and hydrodynamics. The reef zone of a given transect corresponded to the design stratification (Fig. 2). At the transect scale, a more local habitat proxy was defined from the data about depth, substratum and epibenthos. After analysing correlations and redundancies between the 18 measured variables, we retained 8 variables: sand, gravel, boulder, beach rock, coral patch, depth, algal cover and living coral to evaluate similarities between transects through a principal component analysis (PCA). Transects were clustered using an hierarchical ascending classification (HAC). HAC was not performed on the data, but on the factorial coordinates of the PCA to eliminate effects that could mask the structure of interest in the analysis (Pelletier \& Ferraris 2000). The habitat category, i.e. the identifier of the cluster to which a given transect belonged, was considered as a proxy for local habitat.

Partitioning the fish assemblage into species groups. Three criteria were used: mobility, taxonomy and feeding habits. Clupeidae of the genus Sprateloides were excluded from the study because they are pelagic and exhibit an erratic spatial distribution (Kulbicki et al. 1996).

Mobility is generally thought to be a primary behavioural factor in determining potential reserve effect. Following Grimaud \& Kulbicki (1998), 4 groups of species were defined for mobility: (1) territorial species with a very restricted range (usually $<10 \mathrm{~m}^{2}$ ), which are in general aggressive toward intruders, especially conspecifics; (2) sedentary species with a restricted range (10 to several $100 \mathrm{~m}^{2}$ ), which do not aggressively defend territory; (3) weakly mobile species often distributed over the entire reef area (up to several $1000 \mathrm{~m}^{2}$ ), usually not travelling large distances for feeding over short periods of time, but possibly migrating for reproduction; and (4) highly mobile species usually foraging over very large areas, and not restricted to a given reef over a short period of time.

Species belonging to 41 families were recorded during the surveys. Species in a given family are likely to be more similar in terms of trophic, morphologic and demographic features than species belonging to different families. Only 9 families were retained for the analysis: Acanthuridae, Chaetodontidae, Labridae, Lethrinidae, Lutjanidae, Pomacentridae, Scaridae, Serranidae, Siganidae. These were selected either because they were important to fisheries or because they were encountered at a large number of transects, and with non-negligible abundances.

The third criterion was based on feeding habits. Species at a high trophic level are generally those tar-

geted by fishermen, and are thus likely to be sensitive to the reserve status. Feeding habits were expressed in food-type profile in diet. Food types were categorised as nekton, macroinvertebrates, macroalgae, microinvertebrates, microalgae, zooplankton, other plankton, coral and detritus. Species groups with similar diets were built from a factorial correspondence analysis followed by an HAC on diet-composition data. The analysis was carried out on the 372 documented species (out of the 374 species recorded in Abore). The clusters of species obtained will be termed trophic groups in the remainder of the text. For each partitioning criterion, species were assigned to a group and total density per group was computed at each transect.

Assessing the impact of the removal of reserve status. General linear models were fitted to assess the impact of the removal of reserve status and test statistical hypotheses about corresponding effects. A model was fitted for each partitioning criterion and each habitat proxy. Density distribution was normalised by logtransforming the data. Four explanatory factors were included in the model: reserve, year, species group and habitat proxy. The levels of the reserve factor were A (the area closed since 1990) and B (the area open to fishing from 1993 to 1995). The level of the year factor was either 1993 or 1995. The levels of the species group factor depended on the partitioning criterion (mobility, diet and family). The levels of the habitat factor depended on the habitat proxy (reef zone and local habitat). Interactions between factors were considered, except the highest-order interactions. For each criterion, a model ignoring habitat was also fitted to the data; it may be viewed as a null model with respect to habitat. 
a

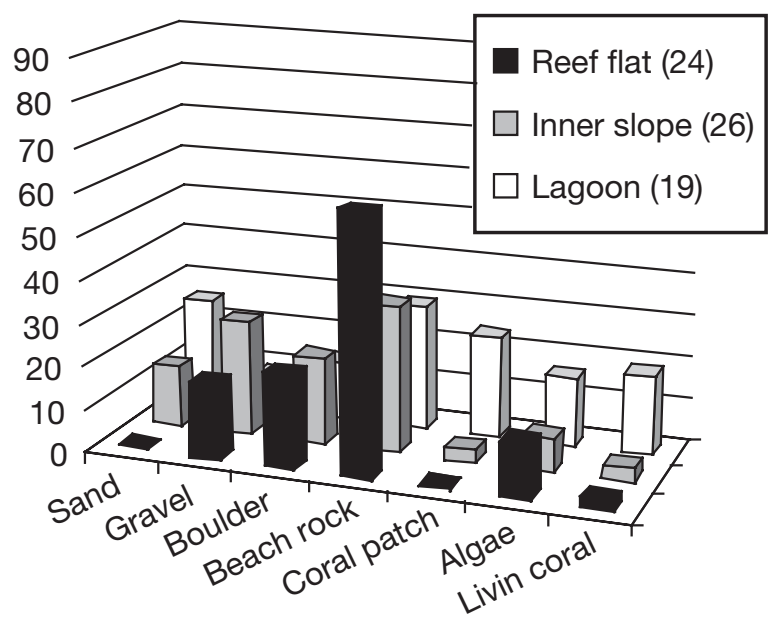

b

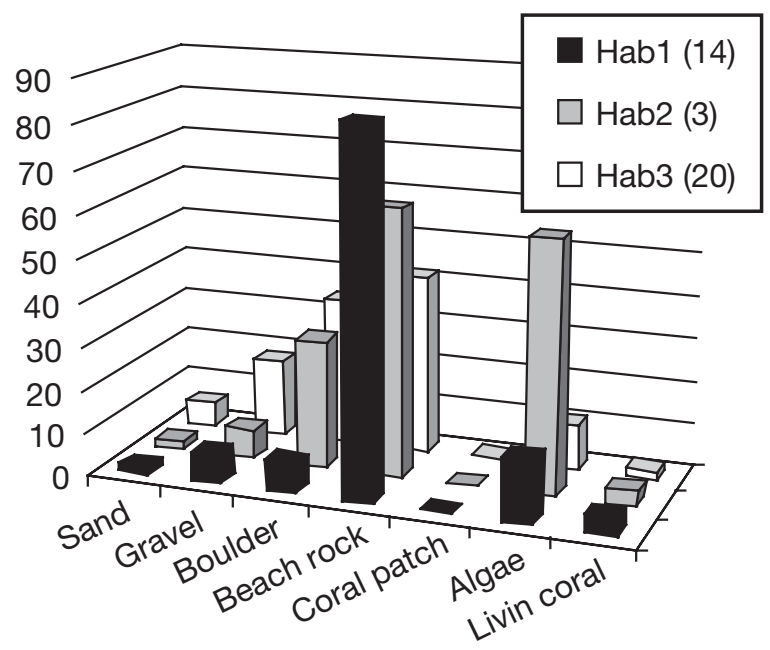

C

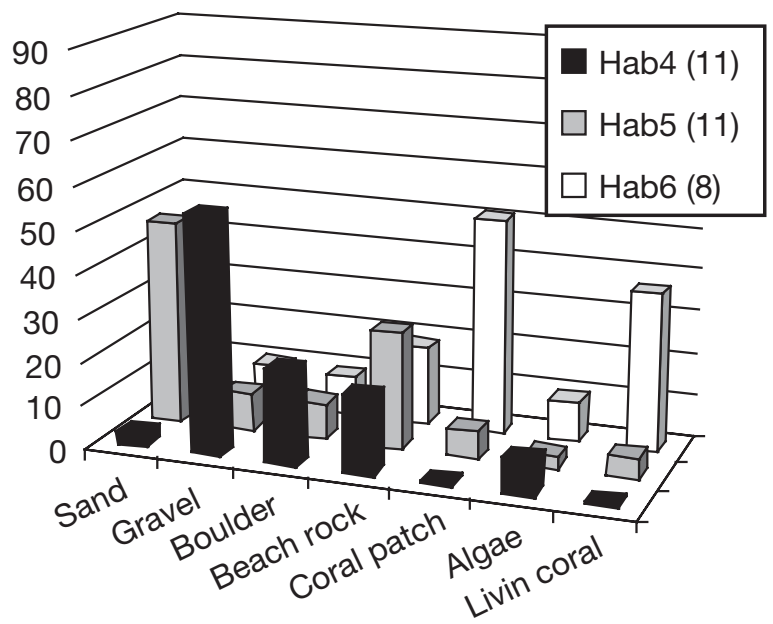

Fig. 4. Description of (a) reef zones and $(\mathrm{b}, \mathrm{c})$ local habitats by substrate composition and living epibenthos cover. The number of transects per reef zone or per local habitat is in parentheses. $y$-axis shows percentage cover
The goodness-of-fit of each model was assessed through multiple $R^{2}$ and global Fisher tests, and the conformity of model residuals to linear model assumptions was checked from standard residual plots and tests (Venables \& Ripley 1997). Once validated, models were selected to eliminate non-significant terms. The selection procedure was based on the comparison of a sequence of models obtained by dropping or adding terms. The models are not necessarily nested, so they cannot be compared using conventional F-tests. Instead, models were compared using Mallows' $C_{p}$ statistic (Mallows 1973):

$$
C_{p}=\mathrm{RSS}+2 \sigma^{2} p
$$

where RSS is the residual sum of squares of the model, $\sigma^{2}$ is the variance of the observations and $p$ is the number of independent parameters in the model. $\sigma^{2}$ is generally estimated from the residual variance of the full model (Venables \& Ripley 1997). $C_{p}$ may be viewed as the residual sum of squares penalised by model complexity, the latter being quantified by the number of parameters of the model.

For each partitioning criterion, the selected models were compared to (1) examine the benefits of accounting for habitat and determine which proxy was the most suitable for explaining changes in density, and (2) assess and interpret the impact of the removal of reserve status. Models were compared across criteria.

The significance of each effect was evaluated through the analysis of variance table based on the Type III sums of squares. The effect of the removal of reserve status was tested through the interaction between the reserve and year factors, and possibly higher-order interactions involving these factors. When these higher-order interactions were significant, the effect depended on a third factor; in particular, a significant interaction between reserve, year and species group meant that species groups were not affected by reserve status in the same way. When only firstorder interactions between reserve and year were significant, fish density responded to reserve status irrespective of the species group.

Adjusted means at the level of the significant interaction term were computed to quantify and test the magnitude and direction of the impact per area and per species group. Simultaneous confidence intervals were estimated for the following differences in adjusted means: (1) difference between Areas A and B in 1993, i.e. prior to the removal of the ban; (2) variation in Area A between 1993 and 1995; (3) variation in Area B between 1993 and 1995; and (4) difference between Areas A and B in 1995. When the secondorder interaction between reserve, year and species group was significant, simultaneous confidence intervals were constructed per species group. For a given 
partitioning criterion, simultaneous intervals were first computed for all species groups together. As this required many comparisons and could hamper the power of the tests, simultaneous intervals were also computed independently for each species group.

In addition to model results, densities and relative differences between years and areas were reported for illustration. Note, however, that relative differences may not reflect the magnitude of differences in adjusted means, due to the log-tranformation, to interactions with other factors and to the unbalanced design.

\section{RESULTS}

\section{Defining habitat from environmental data}

The HAC on the 67 transects with environmental information yielded 6 well-defined clusters, which appear to be strongly characterised by substratum type. Each cluster defined a local habitat (Fig. 4). The first 4 local habitats corresponded to transects with hard bottom (beach rock) or rubble (boulder or gravel), and shallow depth (ranging from 1.3 to $1.9 \mathrm{~m}$, except for the second habitat with an average depth of $8.2 \mathrm{~m}$ ). Habitats 5 and 6 were located in a deeper sandy zone with coral (5.9 and $8.3 \mathrm{~m}$ deep, respectively). The transects of Habitat 6 were characterised by coral patches and a large live coral cover, and were only found in the south-eastern part of Abore in the lagoon stratum. This area is also called 'the forest' because it is composed of submerged reefs of branching Acropora. These habitats were not nested in reef zones, illustrating the small-scale spatial variations of coral reefs (Fig. 5). For example, transects on the reef flat (1.1 $\mathrm{m}$ deep) belonged to 3 local habitats (1, 3 and 4 ), and conversely, a given local habitat may be found in 2 distinct reef zones, e.g. Habitat 5 on both inner slope (2.3 $\mathrm{m}$ deep) and lagoon (8.4 $\mathrm{m}$ deep). The second habitat was only characterised by the sporadic presence of algae at 3 transects in 1995, and was merged with Habitat 1, which exhibited similar substratum characteristics. Each reef zone displayed a more diverse substratum composition and live cover than any local habitat (Fig. 4a).

Note that the number of transects per combination of levels of the factors habitat (whether local habitat or reef zone), reserve and year is unbalanced (Table 1). In the case of reef zone, this is because A and B differ in size, and there are fewer transects in the lagoon stratum. In the case of local habitat, this is due to a finer habitat definition (Table 1), and the effective number of replicates may be low in some local habitats (Table 1). These issues will be further discussed.

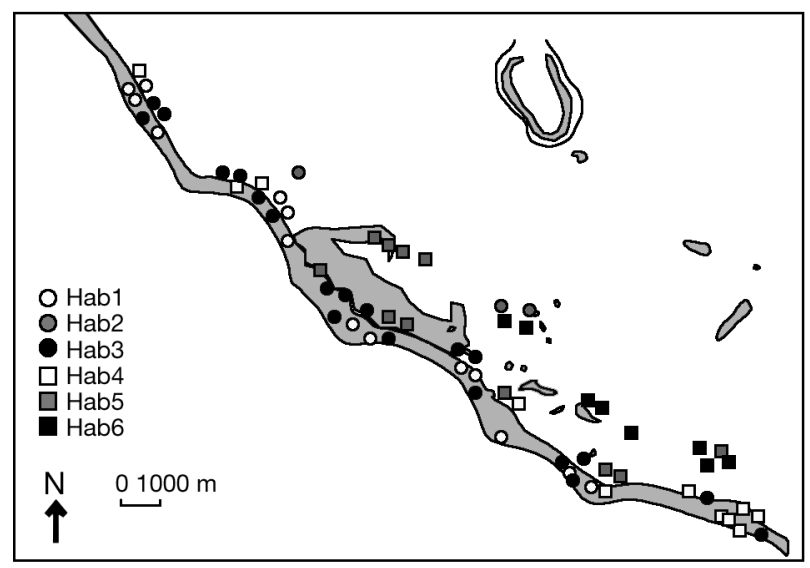

Fig. 5. Assignment of transects to local habitats according to $\mathrm{HAC}$ results

\section{Fish assemblage and species groups}

Three hundred and seventy four species belonging to 41 families were observed, most of them being encountered at a few transects: $50 \%$ of the species were found in less than $10 \%$ of the transects. The number of species observed per transect ranged from 39 to 125, with a mean of 73. Between 1993 and 1995, the total number of species encountered during the survey decreased from 320 to 305 . In 1993, 69\% of species were common to A and B, but only $55 \%$ in 1995 ; hence, species compositions per area differed more in 1995 than in 1993.

The total density per transect ranged between 0.95 and 114 ind. $\mathrm{m}^{-2}$, with a mean of 7.6 ind. $\mathrm{m}^{-2}$. The largest densities observed corresponded to 2 transects with large concentrations of Clupeidae. When this family was excluded from computations, the total density per transect, averaged over the $2 \mathrm{yr}$, dropped to 2.9 ind. $\mathrm{m}^{-2}$, with a mean of 4.0 ind. $\mathrm{m}^{-2}$ in 1993 and 1.7 ind. $\mathrm{m}^{-2}$ in 1995.

The species assemblage was dominated by sedentary species ( $45 \%$ of species), weakly mobile species (31\%), followed by territorial (12\%) and highly mobile species $(12 \%)$.

The families with the largest number of species were Labridae (69 species), Pomacentridae (53), Chaetodontidae (25), Serranidae (23), Scaridae (23) and Acanthuridae (22). The 9 families retained for the analysis comprised 246 species of the 374 observed (i.e. $66 \%$ ), but represented a larger fraction of the total density $(82 \%)$. Each of these families was encountered at each transect, except for Lethrinidae, Lutjanidae and Siganidae (encountered at 52, 24 and 59 transects, respectively). Every family showed a decrease in species number between 1993 and 1995, with the exception of Chaetodontidae, Pomacentridae and Siganidae. 
Table 2. Percent diet composition (mean $\pm \mathrm{SD}$ ) per trophic group. Maximum adult size of species and number of species per group were also reported. The total number of species does not amount to 374, since 3 species lacked information on diet composition

\begin{tabular}{|c|c|c|c|c|c|c|c|}
\hline & $\begin{array}{l}\text { Piscivores } \\
\text { (Pi) }\end{array}$ & $\begin{array}{l}\text { Macro- } \\
\text { carnivores } \\
\text { (MC) }\end{array}$ & $\begin{array}{l}\text { Micro- } \\
\text { carnivores } \\
(\mathrm{mC})\end{array}$ & $\begin{array}{l}\text { Coral } \\
\text { feeders } \\
\text { (Co) }\end{array}$ & $\begin{array}{l}\text { Herbivores } \\
(\mathrm{He})\end{array}$ & $\begin{array}{l}\text { Microalgae } \\
\text { feeders Detri- } \\
\text { tivores (mAD) }\end{array}$ & $\begin{array}{c}\text { Zooplankton } \\
\text { feeders } \\
\text { (Zoo) }\end{array}$ \\
\hline No. of species & 46 & 112 & 50 & 26 & 10 & 73 & 54 \\
\hline \multicolumn{8}{|l|}{ Diet composition (\%) } \\
\hline Nekton & $77 \pm 16$ & $10 \pm 13$ & $2 \pm 5$ & 0 & 0 & $0.1 \pm 0.7$ & $1 \pm 3$ \\
\hline Macroinvertebrates & $21 \pm 17$ & $82 \pm 15$ & $20 \pm 20$ & $2 \pm 4$ & 0 & $2 \pm 7$ & $1 \pm 6$ \\
\hline Microinvertebrates & $0.3 \pm 2.2$ & $6 \pm 10$ & $67 \pm 22$ & $11 \pm 1$ & $3 \pm 4$ & $5 \pm 8$ & $6 \pm 7$ \\
\hline Zooplankton & $1 \pm 4$ & $0.4 \pm 3$ & $3 \pm 7$ & $2 \pm 7$ & 0 & $3 \pm 8$ & $79 \pm 18$ \\
\hline Other plankton & 0 & 0 & 0 & 0 & 0 & 0 & $0.3 \pm 1.5$ \\
\hline Macroalgae & 0 & $0.3 \pm 2$ & $1 \pm 3$ & 0 & $66 \pm 23$ & $3 \pm 6$ & $0.3 \pm 1.5$ \\
\hline Microalgae & 0 & $1 \pm 4$ & $5 \pm 12$ & $7 \pm 9$ & $28 \pm 18$ & $80 \pm 23$ & $11 \pm 14$ \\
\hline Coral & 0 & $0.3 \pm 2$ & $2 \pm 7$ & $77 \pm 20$ & 0 & $1 \pm 4$ & $0.3 \pm 1$ \\
\hline Detritus & 0 & $0.3 \pm 2$ & $1 \pm 3$ & $1 \pm 3$ & $4 \pm 5$ & $6 \pm 9$ & $0.2 \pm 4$ \\
\hline Maximum adult size $(\mathrm{cm})$ & $77 \pm 72$ & $38 \pm 35$ & $17 \pm 12$ & $16 \pm 9$ & $39 \pm 21$ & $24 \pm 21$ & $13 \pm 12$ \\
\hline
\end{tabular}

Table 3. Number of species observed for each partitioning criterion and species group. For mobility groups, Te: territorial; Se: sedentary; WM: weakly mobile; HM: highly mobile. For trophic group abbreviations see Table 2. The total number of species does not amount to 246 (9 families) or 374 (whole assemblage), because some species lacked information on mobility. Numbers

\begin{tabular}{|c|c|c|c|c|c|c|c|c|c|c|c|c|c|}
\hline \multirow[t]{2}{*}{ Family } & \multicolumn{5}{|c|}{ Mobility } & \multicolumn{8}{|c|}{ Trophic group } \\
\hline & $\mathrm{Te}$ & $\mathrm{Se}$ & WM & $\mathrm{HM}$ & Total & $\mathrm{Pi}$ & $\mathrm{MC}$ & $\mathrm{mC}$ & Co & $\mathrm{He}$ & $\mathrm{mAD}$ & Zoo & Total \\
\hline Acanthuridae & 2 & 7 & 6 & 6 & 21 & 0 & 0 & 0 & 0 & 3 & 15 & 4 & 22 \\
\hline Chaetodontidae & 1 & 22 & 0 & 0 & 23 & 0 & 0 & 6 & 19 & 0 & 0 & 0 & 25 \\
\hline Labridae & 3 & 30 & 32 & 0 & 65 & 4 & 33 & 26 & 2 & 0 & 0 & 4 & 69 \\
\hline Lethrinidae & 0 & 1 & 9 & 4 & 14 & 0 & 14 & 0 & 0 & 0 & 0 & 0 & 14 \\
\hline Lutjanidae & 0 & 0 & 6 & 4 & 10 & 3 & 7 & 0 & 0 & 0 & 0 & 0 & 10 \\
\hline Pomacentridae & 23 & 26 & 2 & 0 & 51 & 0 & 0 & 0 & 1 & 0 & 16 & 35 & 52 \\
\hline Scaridae & 0 & 5 & 12 & 6 & 23 & 0 & 0 & 0 & 0 & 1 & 22 & 0 & 23 \\
\hline Serranidae & 2 & 15 & 6 & 0 & 23 & 12 & 8 & 0 & 0 & 0 & 0 & 2 & 22 \\
\hline Siganidae & 0 & 1 & 6 & 1 & 8 & 0 & 0 & 0 & 0 & 5 & 4 & 0 & 9 \\
\hline Total & 31 & 107 & 79 & 21 & 238 & 19 & 62 & 32 & 22 & 9 & 57 & 45 & 246 \\
\hline \multicolumn{14}{|l|}{ Trophic group } \\
\hline $\mathrm{Pi}$ & 0 & 16 & 19 & 11 & 46 & & & & & & & & \\
\hline $\mathrm{MC}$ & 3 & 44 & 42 & 13 & 102 & & & & & & & & \\
\hline $\mathrm{mC}$ & 4 & 26 & 20 & 1 & 51 & & & & & & & & \\
\hline Co & 3 & 19 & 2 & 0 & 24 & & & & & & & & \\
\hline $\mathrm{He}$ & 0 & 1 & 6 & 2 & 9 & & & & & & & & \\
\hline $\mathrm{mAD}$ & 19 & 25 & 19 & 9 & 72 & & & & & & & & \\
\hline Zoo & 13 & 30 & 3 & 8 & 54 & & & & & & & & \\
\hline Total & 42 & 161 & 111 & 44 & 358 & & & & & & & & \\
\hline
\end{tabular}

The analysis of species diets yielded 7 trophic groups (Table 2). In each group, the mean diet included several food items. Groups were named on the basis of their mean diet composition. The fish assemblage was dominated by macrocarnivores $(30 \%)$, algae feeders $(20 \%)$, zooplankton feeders $(14.5 \%)$, microcarnivores $(13.5 \%)$ and piscivores $(12 \%)$. Coral feeders represented $7 \%$ of species. Three species lacking diet data (2 species of Gymnothorax and Epinephelus howlandii) were assigned to the cluster where other species of that genus clustered, i.e. macrocarnivores for $E$. howlandii and piscivores for Gymnothorax.
Once species were assigned to a category for each partitioning criterion, relationships between criteria were examined through contingency tables (Table 3). Territorial species were mainly Pomacentridae, and their preferred diet was micro-algae and zooplankton. Sedentary species included species from almost every family, in particular, Labridae, Pomacentridae, Chaetodontidae and Serranidae. The majority of weakly mobile species were Labridae, Lethrinidae and Scaridae. The most highly mobile species were either macroalgae feeders such as Acanthuridae and Scaridae, or macrocarnivores and piscivores such as 
Table 4. Selected models of log-density per partitioning criterion and per habitat proxy (with goodness-of-fit statistics). 'A:B' represents the interaction between factors A and B. Bold: highly significant effects $(p<0.01)$; underlined: significant effects $(0.05>p>0.01)$; italics: for non-significant effects $(\mathrm{p}>0.05) . C_{p}$ values could not be compared, since the response variable was not the same

\begin{tabular}{|c|c|c|c|c|}
\hline Criterion & Habitat proxy & Model & $R^{2}(\%)$ & $C_{p}$ \\
\hline Mobility & None & mobility + year & 52 & 272 \\
\hline Mobility & Reef zone & mobility + reef zone + year + mobility:reef zone & 60 & 232 \\
\hline Mobility & Local habitat & mobility + reserve + habitat + year + mobility:habitat & 64 & 212 \\
\hline Family & None & reserve + year + family + reserve:year & 58 & 669 \\
\hline Family & Reef zone & $\begin{array}{l}\text { family + reef zone + reserve + year + reserve:year } \\
+ \text { reserve:family + family:reef zone + year:reef zone }\end{array}$ & & \\
\hline \multirow[t]{2}{*}{ Family } & Local habitat & $\begin{array}{l}\text { + reserve:reef zone + reserve:family:reef zone } \\
\text { family + habitat + reserve + year + reserve:year } \\
\text { + reserve:family + family:habitat + year:habitat }\end{array}$ & 67 & 604 \\
\hline & & + year: family + reserve:year:family + year:family:habitat & 74 & 565 \\
\hline Trophic & None & reserve + year + trophic + reserve:year & 69 & 418 \\
\hline Trophic & Reef zone & $\begin{array}{l}\text { trophic }+ \text { reef zone }+ \text { reserve }+ \text { year }+ \text { reserve:year } \\
+ \text { reserve:trophic + trophic:reef zone + reserve:reef zone } \\
+ \text { year:trophic + reserve:trophic:reef zone }\end{array}$ & 79 & 345 \\
\hline \multirow[t]{2}{*}{ Trophic } & Local habitat & $\begin{array}{l}\text { trophic }+ \text { habitat }+ \text { reserve + year } \\
\text { + reserve:year }+ \text { reserve:trophic }+ \text { trophic:habitat }\end{array}$ & & \\
\hline & & + reserve:habitat + year:trophic + reserve:year:trophic & 78 & 362 \\
\hline
\end{tabular}

Lethrinidae and Lutjanidae. In contrast to other families, Scaridae and Lethrinidae mostly comprised a single trophic group (microalgae feeders and macrocarnivores, respectively), but 3 mobility groups (sedentary, weakly and highly mobile). Except for Lutjanidae and Chaetodontidae, every family included species from at least 3 mobility groups. Similarly, every family comprised species from at least 2 trophic groups (except Lethrinidae, which were all macrocarnivores). All trophic groups included more than 1 family (on average 2). Species groups arising from each criterion are, thus, not redundant and provide distinct viewpoints on the fish assemblage.

\section{Evaluation of the removal of reserve status}

In all cases, residuals (not reported) conformed well to linear model assumptions, the global F-test was highly significant and models could be selected. Whatever the partitioning criterion, the fit was substantially improved by the inclusion of a habitat proxy, both in terms of explanatory power (increase in $R^{2}$ ) and in terms of trade-off between model complexity and explanatory power (reduction in $C_{p}$ ) (Table 4). Hence, only models including a habitat proxy are considered. Local habitat led to better fits (lower $C_{p}$, higher $R^{2}$ ) for mobility and family, whereas reef zone yielded slightly better fits for the trophic criterion.

Selected models substantially differed depending on the partitioning criterion. Models selected for mobility did not include a significant interaction between reserve and year (Table 4), but density per mobility group depended on habitat proxy ( $p<0.001)$. This was mostly due to a larger density of territorial species in local Habitats 3, 5 and 6 located in the lagoon reef zone. Density per family led to better fits (higher $R^{2}$ ) than density per mobility group (Table 4 ). Corresponding selected models (Table 4) were more complex than those for mobility; in particular, they comprised first- and second-order interaction terms involving reserve and year factors. The impact of the removal of reserve status was found significant with both habitat proxies. In the case of reef zone, only the reserve $\times$ year effect (first-order interaction) was significant ( $p=0.035)$. Multiple comparisons showed that densities in A and B did not differ in 1993 ( $p>0.05)$; they decreased in both areas over the period $(p=0.05$ in $\mathrm{A}$ and 0.01 in B) and in 1995 density in B was lower than in $A(p=0.05)$. In the case of local habitat, the first-order interaction between reserve and year was not significant, while the second-order effect was $(\mathrm{p}=$ 0.0004). Thus, the impact of the removal of reserve status mainly depended on family, as indicated by differences in adjusted means for the reserve $x$ year $\times$ family effect (Fig. 6). Three patterns of change were observed, depending on family (Fig. 6). First, Scarid densities were not significantly different in Areas A and $B$ in 1993, and they varied in the same way between 1993 and 1995 in the 2 areas. Scaridae were, thus, apparently not affected by the removal of reserve status. Second, for Acanthuridae, Pomacentridae and Chaetodontidae, the density decline between 1993 and 1995 was larger in A than in B; however, it was only significant for Acanthuridae $(p=0.05)$. Third, 4 families exhibited a larger decrease in B than 


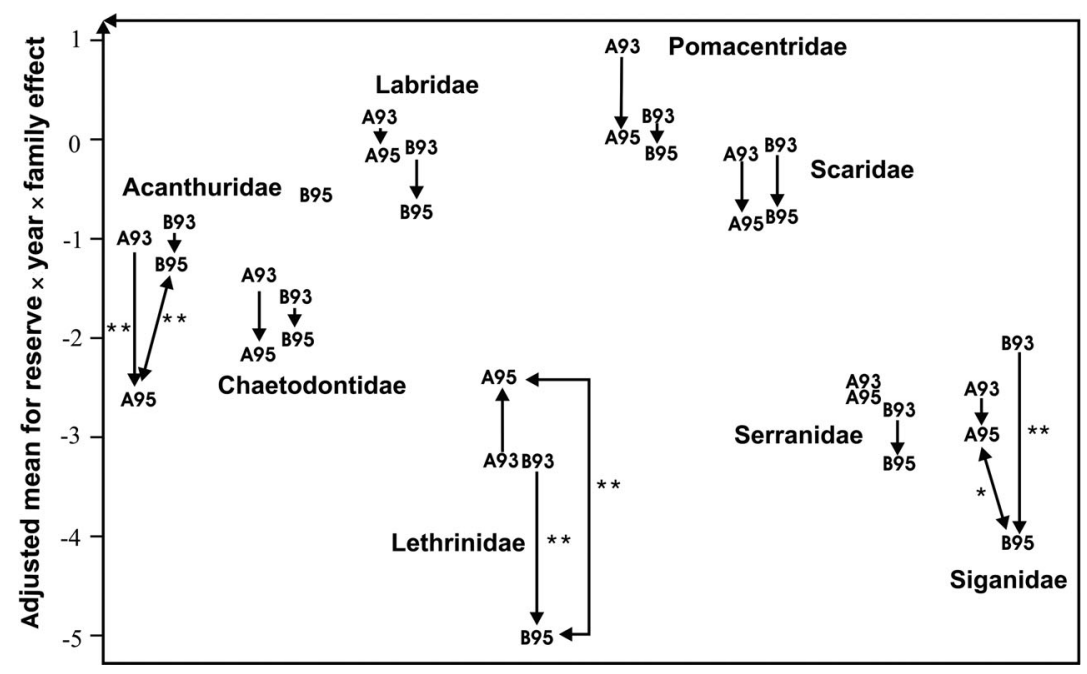

Fig. 6. Adjusted means (log[density]) for the reserve $\times$ year $\times$ family effect in the model of $\log$ (density) per family when the habitat proxy is local habitat. Arrows indicate tested differences (for differences between $\mathrm{A}$ and $\mathrm{B}$, only significant ones are shown and double-headed arrows highlight comparisons between $\mathrm{A}$ and $\mathrm{B}$ of the same year). **: difference significant at the $5 \%$ level in multiple comparisons; *: difference significant at the $5 \%$ level in comparisons carried out per family. The $x$-axis has no quantitative meaning but merely presents species groups side by side with respect to a common $y$-axis

in A: Lethrinidae, Siganidae, Labridae and Serranidae (Fig. 6), corresponding to the expected impact of fish-

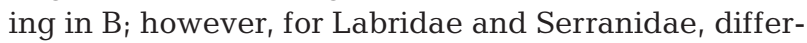
ences over time within a given area, and between areas for a given year, were not significant, even at the $10 \%$ level. Note that in the case of Serranidae, the main exploited species, Epinephelus fasciatus, E. maculatus and Plectropomus leopardus (most exploited), were observed at very few transects. This may explain the lack of significance of the impact of fishing on the family. Differences in densities between A and B were not significant in 1993, except for Lethrinidae $(p=0.01)$ and Siganidae $(p=0.05)$. Unlike all other families, the density of Lethrinidae increased in A between 1993 and 1995 ( $p$ < 0.01). Lethrinidae and Siganidae were the most affected by the removal of reserve status, with highly significant variations in density. Multiple comparisons could not be conducted for Lutjanidae because the family was only observed at 24 transects.

Model results may be confronted with relative differences in densities between years and areas (Table 5). In both areas, densities declined between 1993 and 1995 for all families with the exception of Lethrinidae and Serranidae in Area A. For 5 families out of 9 (Chaetodontidae, Lethrinidae, Scaridae, Serranidae and Siganidae), the relative decline in density was larger in B than in A. If the impact of fishing were assessed from these differences, we would conclude a positive impact for Acanthuridae, Chaetodontidae, Labridae and Lutjanidae, and a negative impact for the other families. Discrepancies between these relative differences in observed densities and model results are due to the log-transformation (only for the magnitude of differences), and from effects involving habitat. In addition, relative differences ignore the fact that the design is unbalanced.
Table 5. Densities (ind. $\mathrm{m}^{-2}$ ) per area, year and family, and (in bold) relative differences in density between areas, $\Delta(\mathrm{B}-\mathrm{A})$, and between years, $\Delta(95-93)$. Relative differences may not reflect the differences in adjusted means (Fig. 6) due to the log-tranformation, the habitat factor and the unbalanced design (see last paragraph of 'Materials and methods')

\begin{tabular}{|c|c|c|c|c|}
\hline Family & Year & $\mathrm{A}$ & $\mathrm{B}$ & $\Delta(\mathrm{B}-\mathrm{A})$ \\
\hline Acanthuridae & $\begin{array}{c}93 \\
95 \\
\Delta(95-93)\end{array}$ & $\begin{array}{l}0.46 \\
0.20 \\
-56\end{array}$ & $\begin{array}{l}0.65 \\
0.35 \\
\mathbf{- 4 6}\end{array}$ & $\begin{array}{l}34 \\
73\end{array}$ \\
\hline Chaetodontidae & $\begin{array}{c}93 \\
95 \\
\Delta(95-93)\end{array}$ & $\begin{array}{l}0.28 \\
0.20 \\
-29\end{array}$ & $\begin{array}{l}0.25 \\
0.15 \\
-\mathbf{3 8}\end{array}$ & $\begin{array}{l}12 \\
22\end{array}$ \\
\hline Labridae & $\begin{array}{c}93 \\
95 \\
\Delta(95-93)\end{array}$ & $\begin{array}{l}1.36 \\
0.76 \\
-45\end{array}$ & $\begin{array}{l}1.05 \\
0.63 \\
-\mathbf{4 0}\end{array}$ & $\begin{array}{l}26 \\
17\end{array}$ \\
\hline Lethrinidae & $\begin{array}{c}93 \\
95 \\
\Delta(95-93)\end{array}$ & $\begin{array}{c}0.05 \\
0.52 \\
+\mathbf{1 0 0 0}\end{array}$ & $\begin{array}{l}0.26 \\
0.08 \\
-67\end{array}$ & $\begin{array}{c}139 \\
84\end{array}$ \\
\hline Lutjanidae & $\begin{array}{c}93 \\
95 \\
\Delta(95-93)\end{array}$ & $\begin{array}{c}0.02 \\
0.0002 \\
-\mathbf{9 9 2}\end{array}$ & $\begin{array}{l}0.05 \\
0.01 \\
-73\end{array}$ & $\begin{array}{c}66 \\
7300\end{array}$ \\
\hline Pomacentridae & $\begin{array}{c}93 \\
95 \\
\Delta(95-93)\end{array}$ & $\begin{array}{l}4.44 \\
1.22 \\
-73\end{array}$ & $\begin{array}{l}1.66 \\
0.89 \\
-46\end{array}$ & $\begin{array}{l}91 \\
27\end{array}$ \\
\hline Scaridae & $\begin{array}{c}93 \\
95 \\
\Delta(95-93)\end{array}$ & $\begin{array}{l}1.19 \\
0.61 \\
-49\end{array}$ & $\begin{array}{l}1.16 \\
0.53 \\
-\mathbf{5 5}\end{array}$ & $\begin{array}{c}2 \\
14\end{array}$ \\
\hline Serranidae & $\begin{array}{c}93 \\
95 \\
\Delta(95-93)\end{array}$ & $\begin{array}{c}0.11 \\
0.12 \\
+\boldsymbol{+}\end{array}$ & $\begin{array}{l}0.18 \\
0.06 \\
-67\end{array}$ & $\begin{array}{l}49 \\
48\end{array}$ \\
\hline Siganidae & $\begin{array}{c}93 \\
95 \\
\Delta(95-93)\end{array}$ & $\begin{array}{l}0.16 \\
0.12 \\
\mathbf{- 2 8}\end{array}$ & $\begin{array}{l}0.17 \\
0.06 \\
-67\end{array}$ & $\begin{array}{c}5 \\
52\end{array}$ \\
\hline
\end{tabular}

Models with trophic groups fitted the data better than models with families (Table 4 ), $R^{2}$ values being systematically higher, albeit with fewer parameters to estimate since the number of trophic groups (7) was 
Fig. 7. Adjusted means (log[density]) for the reserve $\times$ year $\times$ trophic group effect in the model of $\log$ (density) per trophic group when the habitat proxy is local habitat. Arrows indicate tested differences (for differences between A and B, only significant ones are shown and double-headed arrows highlight comparisons between A and B of the same year). **: difference significant at the $5 \%$ level in multiple comparisons; *: difference significant at the $5 \%$ level in comparisons carried out per trophic group. The $x$-axis has no quantitative meaning but merely presents species groups side by side with respect to a common $y$-axis

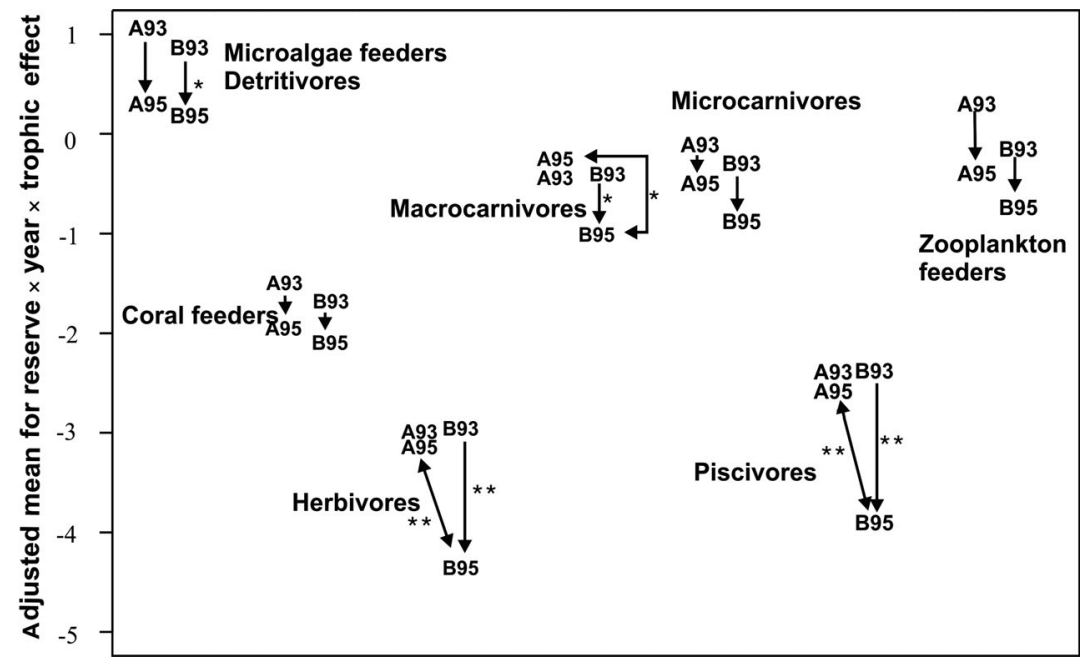

less than the number of families considered (9). In contrast to mobility and taxonomy, reef zone achieved a better fit than local habitat in terms of $R^{2}$ and $C_{p}$ (Table 4). The first-order interaction between reserve and year was significant for reef zone $(p=0.02)$ and for local habitat $(p=0.007)$. The second-order interaction reserve $\times$ year $\times$ trophic group was hardly significant $(p=0.06)$ for local habitat. For reef zones, trophic groups were similarly affected by fishing: densities in A and B were not significantly different in 1993 ( $\mathrm{p}=$ 0.09); they declined significantly in both areas over the period of study $(\mathrm{p}=0.01)$, and in 1995 density was significantly higher in A than in B $(p=0.01)$. For local habitat, density decreased for all trophic groups in both areas, except for macrocarnivores in A (Fig. 7, Table 6). Density declines were only significant in B for herbivores $(p=0.01)$, piscivores $(p=0.01)$, macrocarnivores $(p=0.05)$, and microalgae and detritivores $(p=$ 0.05). Significant differences in 1995 between Areas A and B were found for piscivores $(p=0.01)$, herbivores $(\mathrm{p}=0.01)$ and macrocarnivores $(\mathrm{p}=0.05)$.

Two patterns of change in density could be identified from these results (Table 6). First, similar decreases in both areas between 1993 and 1995 were observed for microalgae and detritus feeders, microcarnivores, zooplankton feeders and coral feeders. From this standpoint, these groups were not significantly affected by the removal of reserve status between 1993 and 1995 . In the second pattern, density significantly decreased between 1993 and 1995, and more in Area B than in Area $A$, as shown by herbivores and piscivores. For macrocarnivores, density even increased in Area A over the same period of time, although not significantly. These 3 groups were clearly affected by fishing in B. The results obtained with Acanthuridae (Fig. 6) did not appear in the trophic groups, since Acanthuridae were mixed with Scaridae in the microalgae and detritus feeder groups (Table 3). Results observed for Lethrinidae and Siganidae could be related to those obtained for macrocarnivores and herbivores, respectively. Although a significant effect of reserve status was found for piscivores and macrocarnivores, no significant effect was detected for Serranidae, which mostly belong to these trophic groups. Lutjanidae were

Table 6. Densities (ind $\mathrm{m}^{-2}$ ) per area, year and trophic group, and relative differences in density between areas, $\Delta(\mathrm{B}-\mathrm{A})$, and between years, $\Delta(95-93)$. Relative differences may not reflect the differences in adjusted means (Fig. 7) due to the log-tranformation, to the habitat factor and to the unbalanced design (see last paragraph of 'Materials and methods')

\begin{tabular}{|c|c|c|c|c|}
\hline Trophic group & Year & $\mathrm{A}$ & B & $\Delta(\mathrm{B}-\mathrm{A})$ \\
\hline Macrocarnivores & $\begin{array}{c}93 \\
95 \\
\Delta(95-93)\end{array}$ & $\begin{array}{c}0.67 \\
1.0 \\
+48\end{array}$ & $\begin{array}{l}0.87 \\
0.48 \\
-45\end{array}$ & $\begin{array}{l}25 \\
52\end{array}$ \\
\hline Microcarnivores & $\begin{array}{c}93 \\
95 \\
\Delta(95-93)\end{array}$ & $\begin{array}{l}1.03 \\
0.54 \\
-\mathbf{4 8}\end{array}$ & $\begin{array}{l}1.99 \\
0.49 \\
-75\end{array}$ & $\begin{array}{c}64 \\
9\end{array}$ \\
\hline Corallivores & $\begin{array}{c}93 \\
95 \\
\Delta(95-93)\end{array}$ & $\begin{array}{l}0.26 \\
0.17 \\
-34\end{array}$ & $\begin{array}{l}0.20 \\
0.13 \\
-35\end{array}$ & $\begin{array}{l}27 \\
25\end{array}$ \\
\hline Herbivores & $\begin{array}{c}93 \\
95 \\
\Delta(95-93)\end{array}$ & $\begin{array}{l}0.14 \\
0.08 \\
-40\end{array}$ & $\begin{array}{l}0.10 \\
0.03 \\
-67\end{array}$ & $\begin{array}{l}28 \\
58\end{array}$ \\
\hline Microalgae feeders & 93 & 3.75 & 2.63 & 35 \\
\hline Detritivores & $\begin{array}{c}95 \\
\Delta(95-93)\end{array}$ & $\begin{array}{l}1.32 \\
-65\end{array}$ & $\begin{array}{l}1.33 \\
-\mathbf{5 0}\end{array}$ & 1 \\
\hline Piscivores & $\begin{array}{c}93 \\
95 \\
\Delta(95-93)\end{array}$ & $\begin{array}{l}0.26 \\
0.06 \\
-76\end{array}$ & $\begin{array}{l}0.14 \\
0.04 \\
-74\end{array}$ & $\begin{array}{l}64 \\
44\end{array}$ \\
\hline Zooplankton feeders & $\begin{array}{l}\text { s } \quad 93 \\
\quad 95 \\
\Delta(95-93)\end{array}$ & $\begin{array}{l}2.69 \\
0.87 \\
-68\end{array}$ & $\begin{array}{l}1.80 \\
0.66 \\
-64\end{array}$ & $\begin{array}{l}40 \\
24\end{array}$ \\
\hline
\end{tabular}


distributed between macrocarnivores ( 7 species) and piscivores (3 species), and we think that their density might have responded in the same way as these groups.

\section{DISCUSSION}

\section{Impact of removal of reserve status on the Abore Reef}

The analysis showed an overall decrease in density and species richness between 1993 and 1995, in both Areas A and B, i.e. irrespective of reserve status. Letourneur et al. (1997) and Wantiez et al. (1997b) tested the effect of the opening of the Abore reserve on several groups of species, ignoring variations in local environment among transects. They found significant decreases in B for both biomass and size, but density decreases were not significant. Sarramegna (2000) raised several hypotheses to explain these overall decreases: (1) a poor recruitment due to an El Niño event in 1994, (2) a reserve impact in both A and B, with fishing in B and subsequent biomass spillover from A to B, and (3) reduced visibility in 1995 due to bad weather conditions during the survey.

Contrary to previous studies at the Abore Reef, we showed that density decrease was significantly larger in the area open to fishing for Lethrinidae, Siganidae, piscivores, herbivores and macrocarnivores. These groups include many fished species; therefore, this effect can be interpreted as a direct consequence of the removal of reserve status. Non-significant results, but with the same trend, were obtained for microcarnivores, Serranidae and Labridae. In the case of Serranidae, a group that includes the main target species, the lack of significance was likely due to the relative scarcity of the species. Many studies have shown that the density of Serranidae substantially increases in reserves (Letourneur 1996, Russ \& Alcala 1996, Chiappone et al. 2000). Note also that Lethrinidae and macrocarnivore densities significantly increased in the reserve over the same period.

In contrast, the density of Acanthuridae decreased significantly more in the reserve area than in the open area. Yet, this family (21 species observed during the survey) includes an important target species for fishers, the unicornfish Naso unicornis, a rather mobile species which constituted the largest catch after the opening of Area B (Sarramegna 2000). This may illustrate the fact that, in the case of mobile species, reserve effects may be difficult to evaluate when the reserve is close to an exploited area. Consequences on fish density may then be more complex than a relative increase in the protected area. Results were similar for Pomacentridae and Chaetodontidae, although variations were not significant. We can hypothesize that this pattern is an inverse effect of reserve status, due to the fact that these groups comprise prey for carnivorous species, e.g. Chromis are prey for Lutjanidae; however, this hypothesis cannot be tested from the data.

The other species groups did not exhibit significant differences due to the removal of reserve status. Several species or species groups were not observed at a sufficient number of transects, resulting in a lack of power for corresponding tests (e.g. Serranidae), or even precluding any test (e.g. Lutjanidae). In this respect, observations directed at exploited species may be useful to complement these data, and would probably reveal significant effects.

Catch and effort data would be helpful to evidence changes due to fishing and possible biomass exportation, but no appropriate data were available, and restoration effects within the reserve cannot be investigated through catch.

\section{Accounting for habitat}

Our approach accounted for habitat-related spatial variability. In all models, the habitat factor explained a substantial part of density variations. This illustrates the need to account for habitat when modelling density, and in particular to properly test the impact of fishing or reserve impact. In many studies aimed at reserve assessment, habitat was included neither in the models nor in the comparisons. This may hamper the quality of the fit and result in decreased statistical power for the tests. This may partly explain the lack of significance often observed in these studies (see Paddack \& Estes 2000 for a discussion). Observed significant interactions between habitat proxies and species group (whatever the partitioning criterion) stressed that species have different habitat requirements depending on their mobility, diet or taxonomy.

As the habitat proxy did not interact with the effect of reserve status (no significant habitat proxy $\times$ reserve $\times$ year interaction), monitoring this impact in a single reference habitat would be sufficient. This may be kept in mind when defining indicators for reserve monitoring and assessment.

Local habitat explained more variability than reef zone in models of density per family. In addition, significant species group-specific effects only occurred when local habitat was considered. Local habitat is more precise than reef zone as it is based on substratum composition. At the scale of local habitat, subtle variations in density per species group were, thus, seen that would go unnoticed at the reef zone scale. However, being defined a posteriori, the local habitat factor could lead to unbalanced designs that could pre- 
vent one from testing some effects. In contrast, the inclusion of a reef zone factor was consistent with the sampling design and allowed almost balanced models. This underlines the need to inventory habitats before designing a survey to monitor fish assemblages. It may be helpful to select transect locations, and the information could be included in the analysis of abundance variability. Habitat may also have been modified by climatic or other environmental events between 2 surveys, e.g. cyclones or algal blooms. Monitoring habitat reduces the risk of misinterpreting changes in habitat as reserve or fishing effects.

\section{Assessing the impact on the entire fish assemblage}

In most existing papers, the impact of reserve or fishing experiments was assessed separately per family (Alcala 1988, Jennings et al. 1996, McClanahan \& Kaunda-Arara 1996, Russ \& Alcala 1998) or for species bearing particular importance in the context of the study (García-Rubies \& Zabala 1990, Letourneur 1996, Edgar \& Barrett 1997, 1999, Johnson et al. 1999). Few studies evaluated reserve effects at the level of trophic groups (but see Harmelin et al. 1995, Russ \& Alcala 1996), and when they did, tests were carried out separately per group.

We proposed an approach based on combined results from multivariate analyses and GLM for the whole fish assemblage. This enabled us to make a general diagnosis about the significance of the impact on fish density. In addition, by considering several explanatory factors in each GLM that are common to species groups, the number of degrees of freedom in the model was increased compared to separate modelling per species group, and so was the ability of the model to detect the impact of interest. Species groups were determined from criteria related to biological and behavioural characteristics of the species. Given these criteria, species in a given group were supposed to be more likely to respond similarly to a change in reserve status. Considering species groups was also made desirable by the large number of fish species and the scarcity of each species.

The models assumed that, for each criterion, the densities of species groups were not correlated. One might argue that the densities of species depend upon each other through functional relationships, and that this results in undesirable correlations between observations. This assumption was justified by the short time range of the experiment, and by the fact that we tested a short-term fishing impact. In the case of restoration effects such as reserve effects, other assumptions about correlations between densities could be needed.
A significant impact of fishing on density was detected for several families and several trophic groups, but not for mobility groups. In addition, models with mobility were less explicative than with trophic groups or taxonomy (but note that there were only 4 mobility groups compared to other criteria). These results show that mobility itself was not sufficient to explain the impact of fishing on density. Species with the same mobility may respond differently to reserve status because of other factors that should be taken into account, such as e.g. targeting by the fishery. Yet, species mobility is hypothesised to be determinant for reserve effects, because mobile species are likely less protected by reserves than others (Allison et al. 1998). Note also that UVC tend to underestimate the abundance of small territorial species (Kulbicki \& Sarramegna 1999), and that the behaviour of exploited fish, which are often large and mobile species, may be affected by fishing (Kulbicki 1998). However, although this could help to interpret different responses according to mobility, this cannot explain the absence of an effect for all mobility groups.

In contrast to mobility, models for trophic groups and taxonomy led to better fits and exhibited a significant impact on the removal of reserve status. This impact depended on species group, so that trophic groups and families seem more appropriate than mobility to partition the fish community for assessing the impact of reserve status. In the literature, reserve effects were often evaluated at the family level (see papers cited first at the beginning of this chapter and Pelletier et al. 2004 for a review). Here, families corresponding to exploited species were logically the most sensitive to reserve status, but counterintuitive effects were also observed (e.g. for Acanthuridae). Other studies (Harmelin et al. 1995, Russ \& Alcala 1996) mainly focused on macrocarnivores and found a significant positive reserve effect. In the present analysis, significant reserve effects, whether positive or negative, were evidenced for several trophic groups.

Comparison of model results across the different partitions of the fish assemblage was helpful to detect the functional groups that were the most sensitive to changes in reserve status. However, further investigation of the relationships between criteria should help to analyse critical changes in fish assemblage. For instance, neither Serranidae nor Labridae showed a significant impact, but both piscivores and macrocarnivores did, while these groups comprise many species from these families. A combination of the criteria used may be relevant for a more precise assessment of the impact under study. In addition, considering the genus, e.g. Epinephelus, could be interesting, but only for the purpose of assessing the impact of fishing on 1 compo- 
nent of fish assemblage. It might also be worthwhile to account for whether the species are exploited or not when constructing species groups. There is always a trade-off between the number of groups in the species classification and the number of parameters in the model.

Compared to many studies in the literature, we found more statistically significant differences in densities for several species groups. There may be several reasons for this.

First, unlike most assessments of reserve or fishing effect, the sampling design includes data collected before and after the impact, both in the impact area and in the control area. Although this design is better suited for impact assessment than those used in most previous studies, it is not a Before/After Control Impact (BACI) design (Stewart-Oaten et al. 1992), which should include several sampling dates before and after the establishment of the reserve or the opening to fishing. Ideally, such effects should be assessed from BACIPS designs to avoid confounded effects due to site-specific temporal variations. BACIPS designs consist of BACI designs performed on several pairs of sites. Implementation of BACIPS designs requires a substantial sampling effort. Relatively few assessments of marine reserves have been based on BACI designs (e.g. Russ \& Alcala 1996). Hoffman \& Dolmer (2000) and Dinmore et al. (2003) used before and after data obtained from regular fishery surveys to assess the effect of partial closures to fishing. To our knowledge, no study relied on a BACIPS design, but such designs should obviously be used whenever possible.

Second, we tested both fishing effect in the area open to fishing and rebuilding of populations after establishment of a reserve. It is likely that fishing in a previously closed area rapidly impacts fish densities, particularly in this case where the opening gave rise to an intense fishing effort. In contrast, the expected rebuilding of populations in a reserve is a slower process. Therefore, our data should a priori be more contrasted than in the case of studies of pure reserve effects. Third, as mentioned above, habitat was measured from additional independent observations, and a habitat factor was included in the model. As habitat explained a substantial part of the variance, fits were improved and consequently the power of statistical tests was increased. In addition, habitat effects were not confounded with effects of reserve status. Lastly, models and tests consider all species groups together (for a given partitioning criterion). As variability could be explained by habitat and because of interactions with the species group factor, the probability of detecting significant differences was consequently increased.

\section{A step toward indicator definition}

Many reserves including the Abore Reef were established to protect fish resources and ecosystems from detrimental human activities: in particular, fishing. Scientific assessments of the effects of reserve status should help managers to make diagnoses and evaluate whether management objectives have been reached or not. This requires appropriate indicators to track changes in fish communities through monitoring and assessment. In the case of the present fishing experiment, indicators should track changes in fish community after partial removal of the reserve status.

Defining indicators requires a metric to be chosen to be measured and monitored, and a model to interpret changes in metrics in relation to the impact studied. Our approach may be helpful to identify metrics that are sensitive to the impact; a metric consisting of a variable (here density) calculated at the scale of a species group for a given criteria. Inferential models of metrics enable the impact studied to be tested (Fig. 3).

Choosing the metric may be facilitated by a priori expectations about the response of a fish community to reserve status (e.g. increased densities or larger fish), but our results show that counterintuitive effects may be observed. They also emphasise that indicators of reserve status must account for habitat. For monitoring purposes, the indicator should be easy to observe during surveys (whether UVC or experimental fishing), e.g. the number of fish per family, or macrocarnivores. The simple models used here, allowed us to identify and test all significant effects explaining changes in density, and they may be transposed to other variables such as biomass, mean size or species richness. Group-specific effects may be analysed and visualised. The approach is not specific to coral-reef fish communities. Although designed for assessing the removal of reserve status, it could be adapted for evaluating reserve effects.

The approach will be applied to other variables or biological parameters such as species richness, biomass, mean size or size distribution, and to other demographic traits, in order to compare a wider range of indicators. The indicators defined in the Abore case will be tested in other reserves of the Noumea lagoon.

Acknowledgements. This study was made possible by the work and dedication of scientists from several institutes who collected the data: R. Galzin (EPHE), Y. Letourneur (COM, University of Marseille), G. Mou-Tham (IRD Nouméa), and S. Sarramegna, P. Thollot, L. Wantiez (LERVEM, Université de Nouvelle-Calédonie). Data collection was funded by la Province Sud (DRN). Additional support was provided by PNEC/ART4. Anonymous referees are gratefully acknowledged for their most helpful comments and suggestions. The authors thank M. C. Tortelier and L. Bloc'h for helping with the figures, and B. Beliaeff and V. Trenkel for reading an earlier version of this paper. 


\section{LITERATURE CITED}

Agardy T (2000) Effects of fisheries on marine ecosystems: a conservationist's perspective. ICES J. Mar Sci 57:761-765

Alcala AC (1988) Effects of marine reserves on coral fish abundances and yields of Philippine coral reefs. Ambio 17: 194-199

Allison GW, Lubchenko J, Carr MH (1998) Marine reserves are necessary but not sufficient for marine conservation. Ecol Appl 8:S79-S92

Batistini R, Bourrouilh F, Chevalier JP, Coudray J and 20 others (1975) Eléments de terminologie récifale indopacifique. Tethys 7:1-111 (in French with English abstract)

Bell JD (1983) Effects of depth and marine reserve fishing restrictions on the structure of a rocky reef fish assemblage in the North-western Mediterranean sea. J Appl Ecol 20:357-369

Bell JD, Galzin R (1984) Influence of live coral cover on coralreef fish communities. Mar Ecol Prog Ser 15:265-274

Botsford LW, Castilla JC, Peterson CH (1997) The management of fisheries and marine ecosystems. Science 277: 509-514

Castilla JC, Bustamante RH (1989) Human exclusion from rocky intertidal of Las Cruces, central Chile: effects on Durvillaea antartica (Phaeophyta, Durvilleales). Mar Ecol Prog Ser 50:203-214

Chabanet P, Ralambondrainy H, Amanieu M, Faure G, Galzin $\mathrm{R}$ (1997) Relationships between coral reef substratum and fish. Coral Reefs 16:93-102

Chapman MR, Kramer DL (1999) Gradients in coral reef fish density and size across the Barbados marine reserve boundary: effects of reserve protection and habitat characteristics. Mar Ecol Prog Ser 181:81-96

Chiappone M, Sluka R, Sealey S (2000) Groupers (Pisces: Serranidae) in fished and protected areas of the Florida Keys, Bahamas and northern Caribbean. Mar Ecol Prog Ser 198: 261-272

Christensen V, Pauly D (1992) ECOPATH II: a software for balancing steady-state models and calculating network characteristics. Ecol Model 61:169-185

Dalzell P, Adams TJH, Polunin NVC (1996) Coastal fisheries in the Pacific Islands. Oceanogr Mar Biol Annu Rev 34: 395-531

Dinmore TA, Duplisea DE, Rackham BD, Maxwell DL, Jennings $S$ (2003) Impact of large-scale area closure on patterns of fishing disturbance and the consequences for benthic communities. ICES J Mar Sci 60:371-380

Dugan JE, Davis GE (1993) Applications of marine refugia to coastal fisheries management. Can J Fish Aquat Sci 50: 2029-2042

Edgar GJ, Barrett NS (1997) Short term monitoring of biotic change in Tasmanian marine reserves. J Exp Mar Biol Ecol 213:261-279

Edgar GJ, Barrett NS (1999) Effects of the declaration of marine reserves on Tasmanian reef fishes, invertebrates and plants. J Exp Mar Biol Ecol 242:107-144

FAO (1995) Precautionary approach to fisheries. FAO Fisheries Technical Paper 350/1, FAO, Rome

García-Charton JA, Pérez-Ruzafa A (1999) Ecological heterogeneity and the evaluation of the effects of marine reserves. Fish Res 42:1-20

García-Charton JA, Williams LD, Pérez Ruzafa A, Milazzo M and 5 others (2000) Evaluating the ecological effects of Mediterranean protected areas: habitat, scale and the natural variability of ecosystems. Environ Conserv 27: 159-178

García-Charton JA, Pérez-Ruzafa A, Sànchez-Jerez P, Bayle-
Sempere JT, Reñones O, Moreno D (2004) Multi-scale spatial heterogeneity, habitat structure, and the effect of marine reserves on Western Mediterranean rocky reef fish assemblages. Mar Biol 144:161-182

García-Rubies AG, Zabala M (1990) Effects of total fishing prohibition on the rocky fish assemblages of Medes Islands marine reserve (Mediterranean). Sci Mar 54: $317-328$

Gerber LR, Botsford LW, Hastings A, Possingham HP, Gaines SD, Palumbi SR, Andelman S (2003) Population models for marine reserve design: a retrospective and prospective synthesis. Ecol Appl 13:S47-S64

Grimaud J, Kulbicki M (1998) Influence de la distance à l'océan sur les peuplements ichtyologiques des récifs frangeants de Nouvelle-Calédonie. CR Acad Sci Paris Sci Vie 321:923-931

Halpern B (2003) The impact of marine reserves: do reserves work and does reserve size matter? Ecol Appl 13: S117-S137

Harmelin JG, Bachet F, Garcia F (1995) Mediterranean marine reserves: fish indices as tests of protection efficiency. PSZN I: Mar Ecol 16:233-250

Hoffmann E, Dolmer P (2000) Effects of closed areas on distribution of fish and epibenthos. ICES J Mar Sci 57: $1310-1314$

Jennings S, Kaiser MJ (1998) The effects of fishing on marine ecosystems. Adv Mar Biol 34:2-27

Jennings S, Marshall SS, Polunin NVC (1996) Seychelles' protected areas: comparative structure and status of reef fish communities. Biol Conserv 75:201-209

Johnson DR, Bohnsack JA, Funicelli NA (1999) The effectiveness of an existing no-take fish sanctuary within the Kennedy Space Center, Florida. N Am J Fish Manag 19: 436-453

Jones GP, Syms C (1998) Disturbance, habitat structure and the ecology of fishes on coral reefs. Austral J Ecol 23: 287-297

Kelly S, Scott D, McDiarmid AB, Babcock RC (2000) Spiny lobster, Jasus edwardsii, recovery in New Zealand marine reserves. Biol Conserv 92:359-369

Kulbicki M (1998) How acquired behavior of commercial reef fish may influence results obtained from visual censuses. J Exp Mar Biol Ecol 222:11-30

Kulbicki M, Rivaton J (1997) Inventaire des poissons lagonaires et récifaux de Nouvelle-Calédonie. Cybium 21: S81-S98 (in French with English abstract)

Kulbicki M, Sarramegna S (1999) Comparison of density estimates derived from strip transect and distance sampling for underwater visual census: a case study of Chaetodontiidae and Pomacanthidae. Aquat Living Resour 12: 315-325

Kulbicki M, Galzin R, Letourneur Y, Mou Tham G, Sarramegna S, Thollot P, Wantiez L, Chauvet C (1996) Les peuplements de poissons de la réserve marine du récif Aboré (Nouvelle-Calédonie): composition spécifique, structures trophique et démographique avant l'ouverture à la pêche. Doc Sci Tech ORSTOM Nouméa 1, Nouméa, $\mathrm{NC}$

Labrosse P, Letourneur Y, Kulbicki M, Magron F (1999) A new database on the biology and ecology of lagoon and reef fishes of the south pacific. Example of its use on the ecology of commercial herbivorous fishes. Proc 5th Indo-Pac Fish Conf 1:657-672

Lauck T, Clark CW, Mangel M, Munro GR (1998) Implementing the precautionary principle in fisheries management through the implementation of marine reserves. Ecol Appl 8:572-578 
Letourneur Y (1996) Réponse des peuplements et populations de poissons aux réserves marines: le cas de l'île de Mayotte, Océan Indien occidental. Ecoscience 3:442-450 (in French with English abstract)

Letourneur Y, Kulbicki M, Sarramegna S, Thollot P, Wantiez L, Galzin R, Chauvet C (1997) The Abore marine reserve (New Caledonia) - 2: analysis of the fish diversity. Proc 5th Indo-Pac Fish Conf (Abstracts), p 60

Mallows CL (1973) Some comments on $C_{p}$. Technometrics 12: 591-612

McClanahan TR, Kaunda-Arara B (1996) Fishery recovery in a coral-reef marine park and its effect on the adjacent fishery. Conserv Biol 10:187-199

McCormick MI, Choat JH (1987) Estimating total abundance of a large temperate-reef fish using visual strip transects. Mar Biol 96:469-478

McCoy ED, Bell SS (1991) Habitat structure and diversification of a complex topic. In: Bell SS, Mc Coy ED, Mushinsky HR (eds) Habitat structure. The physical arrangement of objects in space, p 3-27, Chapman \& Hall, New York

Ohman M, Rajasuriya A, Svensson S (1998) The use of butterflyfishes (Chaetodontidae) as bio-indicators of habitat structure and human disturbance. Ambio 27:708-716

Paddack MJ, Estes JA (2000) Kelp forest fish populations in marine reserves and adjacent exploited areas of central California. Ecol Appl 10:855-870

Pauly D, Froese R (1991) Fishbase: assembling information on fish. NAGA, ICLARM Q 14:10-11

Pelletier D, Ferraris J (2000) A multivariate approach for defining fishing tactics from commercial catch and effort data. Can J Fish Aquat Sci 57:1-15

Pelletier D, Mahévas S, Poussin B, Bayon J, André P, Royer JC (2001) A conceptual model for evaluating the impact of spatial management measures on the dynamics of a mixed fishery. In: Kruse GH, Bez N, Booth T, Dorn M and 6 others (eds) Spatial processes and management of marine populations, University of Alaska Sea Grant, AK-SG00-04, Fairbanks, AK, p 53-66

Pitcher TJ, Hart PJB, Pauly D (1998) Reinventing fisheries management. Fish and Fisheries Series. 23. Kluwer Academic, Dordrecht

Rakitin A, Kramer DL (1996) Effect of a marine reserve on the distribution of coral reef fishes in Barbados. Mar Ecol Prog Ser 131:97-113

Roberts CM, Polunin NVC (1991) Are marine reserves effec-

Editorial responsibility: Otto Kinne (Editor-in-Chief), Oldendorf/Luhe, Germany tive in the management of reef fisheries? Rev Fish Biol Fish 1:65-91

Roberts CM, Bohnsack JA, Gell F, Hawkins JP, Goodridge R (2001) Effects of marine reserves on adjacent fisheries. Science 294:1920-1923

Russ GR (2002) Yet another review of marine reserves as reef fishery management tools. In: Sale PF (ed) Coral reef fishes. Elsevier Science, San Diego, CA, p 421-443

Russ GR, Alcala AC (1996) Marine reserves: rates and patterns of recovery and decline of large predatory fish. Ecol Appl 6:947-961

Russ GR, Alcala AC (1998) Natural fishing experiments in marine reserves 1983-1993: community and trophic responses. Coral Reefs 17:383-397

Sale P (1998) Appropriate spatial scales for studies of reef-fish ecology. Austral J Ecol 23:202-208

Samoilys MA (1988) Abundance and species richness of coral reef fish on the kenyan coast: the effects of protective management and fishing. Proc 6th Int Coral Reef Symp 2: 261-266

Sarramegna S (2000) Contributions à l'étude des réserves marines du lagon sud-ouest de Nouvelle-Calédonie: influence des différents statuts de protection sur la structure des peuplements ichtyologiques. PhD Dissertation, Université de Nouvelle-Calédonie, Nouméa, NC

Stewart-Oaten A, Bence JR, Osenberg CW (1992) Assessing effects of unreplicated perturbations: no simple solutions. Ecology 73:1396-1404

Sumaila UR, Guénette S, Alder J, Chuenpagdee R (2000) Addressing ecosystem effects of fishing using marine protected areas. ICES J Mar Sci 57:752-760

Venables WN, Ripley BD (1997) Modern applied statistics with S-PLUS, 2nd ed. Springer, New York

Walters CJ, Hilborn R (1976) Adaptive control of fishing systems. J Fish Res Bd Can 33:145-159

Wantiez L, Thollot P, Kulbicki M (1997a) Effects of marine reserves on coral reef fish communities from five islands in New Caledonia. Coral Reefs 16:215-224

Wantiez L, Thollot P, Kulbicki M, Chauvet C, Galzin R, Letourneur Y, Sarramegna S (1997b) The Abore marine reserve (New Caledonia) - 3: structure of the reef fish community. Proc 5th Indo-Pac Fish Conf (Abstracts), p 110

Ward TJ, Vanderklift MA, Nicholls AO, Kenchington RA (1999) Selecting marine reserves using habitats and species assemblages as surrogates for biological diversity. Ecol Appl 9:691-698

Submitted: May 12, 2004; Accepted: August 26, 2004

Proofs received from author(s): March 17, 2005 